\title{
Formation of Hot Tear Under Controlled Solidification Conditions
}

\author{
TUNGKY SUBROTO, ALEXIS MIROUX, LIONEL BOUFFIER, \\ CHARLES JOSSEROND, LUC SALVO, MICHEL SUÉRY, DMITRY G. ESKIN, \\ and LAURENS KATGERMAN
}

\begin{abstract}
Aluminum alloy 7050 is known for its superior mechanical properties, and thus finds its application in aerospace industry. Vertical direct-chill (DC) casting process is typically employed for producing such an alloy. Despite its advantages, AA7050 is considered as a "hardto-cast" alloy because of its propensity to cold cracking. This type of cracks occurs catastrophically and is difficult to predict. Previous research suggested that such a crack could be initiated by undeveloped hot tears (microscopic hot tear) formed during the DC casting process if they reach a certain critical size. However, validation of such a hypothesis has not been done yet. Therefore, a method to produce a hot tear with a controlled size is needed as part of the verification studies. In the current study, we demonstrate a method that has a potential to control the size of the created hot tear in a small-scale solidification process. We found that by changing two variables, cooling rate and displacement compensation rate, the size of the hot tear during solidification can be modified in a controlled way. An X-ray microtomography characterization technique is utilized to quantify the created hot tear. We suggest that feeding and strain rate during DC casting are more important compared with the exerted force on the sample for the formation of a hot tear. In addition, we show that there are four different domains of hot-tear development in the explored experimental window-compression, microscopic hot tear, macroscopic hot tear, and failure. The samples produced in the current study will be used for subsequent experiments that simulate cold-cracking conditions to confirm the earlier proposed model.
\end{abstract}

DOI: $10.1007 / \mathrm{s} 11661-014-2220-6$

(C) The Minerals, Metals \& Materials Society and ASM International 2014

\section{INTRODUCTION}

AA7050 belongs to a group of high-strength aluminum alloys. Thanks to its superior mechanical properties, it is widely used in aerospace industry. ${ }^{[1]}$ The main production route of this alloy includes direct-chill (DC) casting. ${ }^{[2]}$ In such a process, a just-solidified billet shell is directly cooled with water. Consequently, a severe thermomechanical condition is created inside the billet, involving high temperature gradients, inhomogeneous contraction, and tensile thermal stresses. All these make the billet prone to cracking. From previous research, AA7050 is known as a "hard-to-cast" alloy

TUNGKY SUBROTO, Ph.D. Student, and ALEXIS MIROUX, Senior Researcher, are with the Materials innovation institute (M2i), Mekelweg 2, Delft $2628 \mathrm{CD}$, The Netherlands and also with the Department of Materials Science and Engineering, Delft University of Technology, Mekelweg 2, Delft 2628 CD, The Netherlands. Contact e-mail: t.subroto@m2i.nl; tungky.subroto@gmail.com LIONEL BOUFFIER, Ph.D. Student, CHARLES JOSSEROND, Engineer, LUC SALVO, Associate Professor, and MICHEL SUÉRY, Professor, are with the Grenoble INP, SIMaP/GPM2, UMR CNRS 5266, UJF, BP46, 38402, Saint-Martin d'Hères Cedex, France. DMITRY G. ESKIN, Professor, is with the BCAST, Brunel University, Uxbridge, Middlesex UB8 3PH, U.K. LAURENS KATGERMAN, Professor, is with the Department of Materials Science and Engineering, Delft University of Technology.

Manuscript submitted October 3, 2013. because of its susceptibility to both hot and cold cracking ${ }^{[3]}$ Hot tears or cracks form above the solidus while cold cracks form below the solidus. Cold-cracking occurrence is seemingly random and difficult to predict. In addition, the propagation of such cracks is usually catastrophic. Therefore, not only does it reduce the yield of DC casting production and increases the production cost but this type of cracking can also induce severe damage to personnel and equipment in the vicinity of the casting area. ${ }^{[4,5]}$

Progress in predicting the cold-cracking occurrence was recently made using a fracture mechanics approach. $^{[6,7]}$ The developed criterion for the crack states that solidification defects that survive until the ingot is fully solid could become the initiation point of the cold crack if they exceed a critical crack size. It was also suggested that underdeveloped or microscopic hot tear could be such an initiation point of the catastrophic cold crack. However, the validation of this assumption requires the presence of a defect of known size before the cold-cracking testing. The development of an experimental technique that would allow creating a hot tear under controlled conditions is the subject of the current article.

Recent experimental advances give the possibility to perform high-resolution and in situ observation of hot tearing. ${ }^{[8-10]}$ However, most of these studies are directed toward the development of hot tearing up to complete 
failure. Our main focus is on the contrary, on undeveloped hot tears that remain within the billet and could act as a nucleation point for a catastrophic cold crack.

The current article demonstrates an experimental technique that has potential to control the size of the created microscopic hot tears by controlling test parameters such as cooling rate and deformation rate in a small-scale casting process. The sizes and location of created hot tears are measured by X-ray microtomography (XMT) technique after full solidification of the sample. Subsequently, such samples with created hot tear within can be used for a test that simulates coldcracking occurrence at lower temperature. The result from such a test can be used to verify the existing coldcrack criterion which will be the next step of our research.

\section{EXPERIMENTAL SETUP}

\section{A. Material}

Cylindrical billets $315 \mathrm{~mm}$ in diameter were produced by DC casting. The chemical composition of the billets is shown in Table I. The melt was first degassed in the furnace at $1003 \mathrm{~K}\left(730^{\circ} \mathrm{C}\right)$ and then cast with a conventional DC casting mold. The casting temperature was approximately $953 \mathrm{~K}\left(680^{\circ} \mathrm{C}\right)$. The billets were grain refined by using a standard A15Ti1B master alloy with the addition rate of $2 \mathrm{~kg} /$ ton. The solidification path of the alloy was obtained from JMat-Pro software (Sente Software Ltd., United Kingdom) using Scheil approximation. This calculation was provided by Tata Steel Research and Development (shown in Figure 1).

\section{B. Mechanical Experimental Setup}

The experiments were performed at the SIMaPGPM2 laboratory in Grenoble INP, and the setup used for the tests is schematically depicted in Figure 2(a). An Adamel DY34 machine equipped with a $2-\mathrm{kN}$ load cell was utilized. The samples were machined from the billet as cylinders with a diameter of $9.5 \mathrm{~mm}$ and length of $120 \mathrm{~mm}$. The temperature was controlled using a Eurotherm $^{\mathrm{TM}}$ temperature controller and measured by a K-type thermocouple of $0.5-\mathrm{mm}$ diameter located at mid-length of the sample at a depth of $2 \mathrm{~mm}$ from the surface.

The testing cycle of the experiment follows Figure 2(b). First, the sample was heated by induction to the fully liquid state or $T_{\text {liquidus }}\left[908 \mathrm{~K}\left(635^{\circ} \mathrm{C}\right)\right]$ at a heating rate of $2 \mathrm{~K} / \mathrm{s}\left(2^{\circ} \mathrm{C} / \mathrm{s}\right)$. Since the ends of the sample were cooled down by water circulation, a temperature gradient developed along the length of the sample with the hottest point at mid-length where the temperature was recorded. During heating, the thermal expansion of the sample was accommodated by the displacement of the jaw, thus minimizing the imposed force to the sample (Phase-I in Figure 2(b)). When the center of the sample reached the liquidus temperature, it was held for 30 seconds to stabilize the temperature gradient (II). At this point, the jaw displacement due to thermal expansion of the sample is in average $0.82 \mathrm{~mm}$. Subsequently, the sample was cooled down at controlled cooling rates that resembled the cooling rates at the center part of a billet during DC casting: between $0.1 \mathrm{~K} / \mathrm{s}$ and $1.0 \mathrm{~K} / \mathrm{s}\left(0.1{ }^{\circ} \mathrm{C} / \mathrm{s}\right.$ and $\left.1.0^{\circ} \mathrm{C} / \mathrm{s}\right)$. Two types of jaw-displacement modes have been used during this phase (III). For the first setting, named "constrained," the jaw movement was locked so that the force was built up because of thermal contraction. In the second setting, force compensation was provided by moving the jaws toward each other at a constant speed to reduce the force generated by the thermal contraction. The compensation speeds, or displacement compensation rates, used in the current study are between $0.00018 \mathrm{~mm} / \mathrm{s}$ and $0.0009 \mathrm{~mm} / \mathrm{s}$. In both cases, when the temperature reached the nonequilibrium solidus temperature or $T_{\text {nes }}$ $\left[738 \mathrm{~K}\left(465^{\circ} \mathrm{C}\right)\right]$, the force level in the sample was minimized, and the sample was cooled down to room temperature at the same cooling rate (IV). The forceminimizing step at the last phase was also to ensure that only hot tears were produced inside the sample and that such a defect did not develop further during cooling in the fully solid state. ${ }^{[11]}$ At the end of the test, the average sample length increased by $0.21 \mathrm{~mm}$. All the variables of

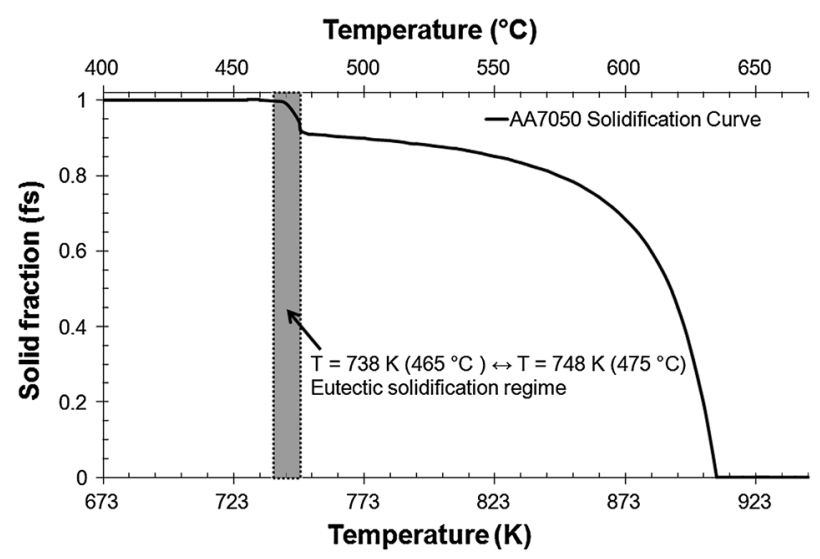

Fig. 1-Solidification path of AA7050 obtained from JMat-Pro software. The eutectic-solidification regime, between temperatures of equilibrium solidus $748 \mathrm{~K}\left(475^{\circ} \mathrm{C}\right)$ or solid fraction $=0.94$ and nonequilibrium solidus $\left(T_{\text {nes }}\right) 738 \mathrm{~K}\left(465^{\circ} \mathrm{C}\right)$ or solid fraction $=1.0$ is shown by the enclosed gray region.

Table I. Chemical Composition of AA7050 Billets

\begin{tabular}{lcccccccccccc}
\hline \multicolumn{10}{c}{ Elements, wt pct } \\
\hline $\mathrm{Zn}$ & $\mathrm{Cu}$ & $\mathrm{Mg}$ & $\mathrm{Zr}$ & $\mathrm{Fe}$ & $\mathrm{Mn}$ & $\mathrm{Si}$ & $\mathrm{Ti}$ & $\mathrm{Cr}$ & $\mathrm{Al}$ \\
\hline 6.15 & 2.2 & 2.1 & 0.13 & 0.07 & 0.04 & 0.04 & 0.03 & $<0.01$ & balance \\
\hline
\end{tabular}




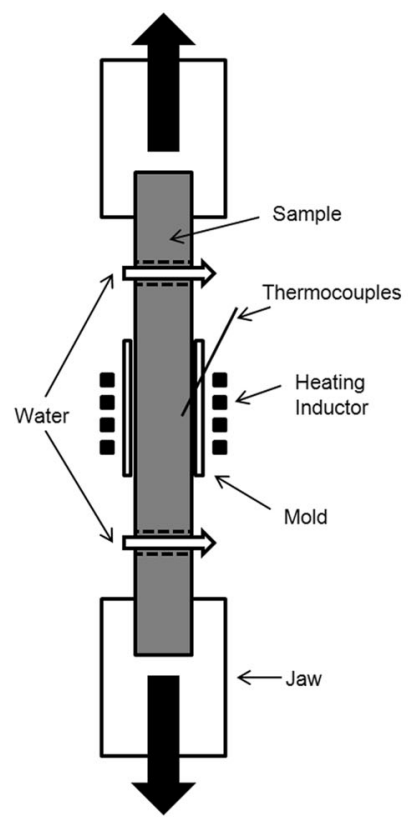

(a)

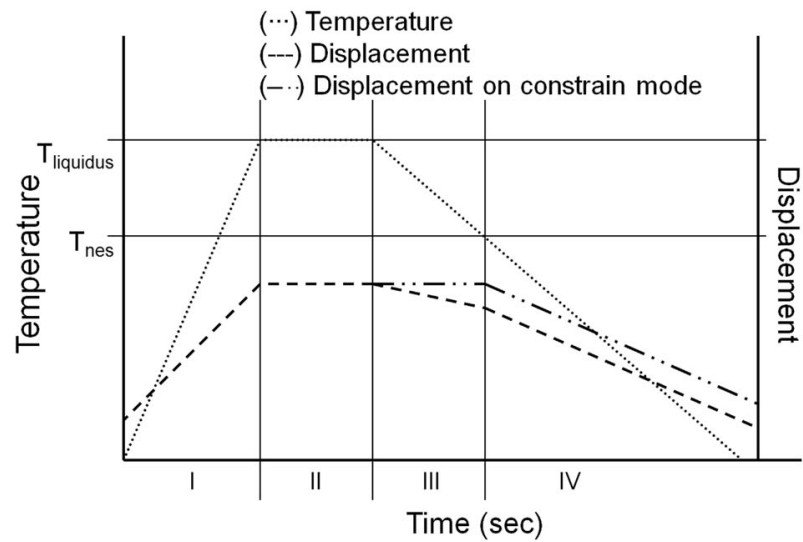

(b)

Fig. 2-Schematic of tensile test setup (a) and test cycle (b), indicating both temperature (bullet points) and jaw displacement (dashed line)

the experiment (temperature, jaw displacement, and load) were recorded in real time during the test.

We made separate tests to observe the axial and radial temperature distribution in the sample during the heating cycle of the test as shown in Figure 2(b). In these tests, we simulate the heating phase, holding at near solidus temperature $\left[733 \mathrm{~K}\left(460^{\circ} \mathrm{C}\right)\right]$ and then cooling with prescribed cooling rates similar to those of the thermomechanical tests. To observe the axial temperature distribution, we used two thermocouples along the center-axis; one was at the mid-length, and the other was $10 \mathrm{~mm}$ off the mid-length. Using linear extrapolation to $T_{\text {liquidus, }}$, the temperature at $10 \mathrm{~mm}$ off midlength was approximately $96 \mathrm{~K}\left(96^{\circ} \mathrm{C}\right)$ lower than at the mid-length. To observe radial temperature distribution, we performed a test with two thermocouples at the mid-length of the sample: one was placed at the center-axis, and the other placed $2 \mathrm{~mm}$ below the surface. From such a test, in the heating phase, there was not much temperature variation (in the end of the heating phase, by linear extrapolation to $T_{\text {liquidus }}$, the temperature at the center-axis was $5 \mathrm{~K}\left(5^{\circ} \mathrm{C}\right)$ lower compared with the temperature at $2 \mathrm{~mm}$ below the surface). During the holding phase, the center of the sample was approximately $3.5 \mathrm{~K}\left(3.5^{\circ} \mathrm{C}\right)$ cooler than at $2 \mathrm{~mm}$ below the surface. However, there was electromagnetic stirring effect on the liquid phase of the alloy caused by the induction coil that might have helped in homogenizing the temperature distribution across the radial direction. We also measured the difference of the cooling rates between the center-axis and $2 \mathrm{~mm}$ below the surface during the cooling phase. The average cooling rate is homogeneous between the center-axis and $2 \mathrm{~mm}$ below the surface - the difference of average cooling rate between these two points was approximately $0.005 \mathrm{~K} / \mathrm{s}\left(0.005^{\circ} \mathrm{C} / \mathrm{s}\right)$ independent of the used cooling rates. This accuracy is good for the comparison of the used cooling rates.

\section{Hot-Tear Characterization via XMT}

The center of the tested samples, where most deformation occurs, was imaged using a Phoenix Nanotom ${ }^{\circledR}$ X-Ray microtomography scanner. The XMT imaging was carried out in the Civil Engineering and Geoscience Faculty of Delft University of Technology. During the rotation of the sample over $360 \mathrm{deg}, 1440$ transmission images were recorded. The voxel size of the image was set to $5 \mu \mathrm{m}$ (length of each side). After data acquisition, three-dimensional (3D) images of the sample were reconstructed using VG Studio 2.0 software. Further image analysis in the current study was carried out using Fiji image analysis software. ${ }^{[12]}$

\section{RESULTS AND DISCUSSION}

\section{A. Mechanical Response}

When the sample reaches phase III (refer to Figure 2(b)) and starts cooling down while being constrained, we typically observe the start of mechanical response at approximately $873 \mathrm{~K}\left(600{ }^{\circ} \mathrm{C}\right)$ (solid fraction or $\left.f_{\mathrm{s}}=0.7\right)$. The load starts to be appreciable around $848 \mathrm{~K}\left(575^{\circ} \mathrm{C}\right)\left(f_{\mathrm{s}}=0.8\right)$ and will gradually develop as the solid fraction increases. Figure 3(a) shows for different cooling rates, the average force values at different solid fractions from at least four tests. Several stages can be distinguished from the slope of force increase; in general, between $f_{\mathrm{s}}=0.8$ and 0.85 , the slope is shallow; such a slope becomes steeper between $f_{\mathrm{s}}=0.85$ and 0.9 ; it subsequently becomes shallow again between $f_{\mathrm{s}}=0.9$ and 0.97 (in this regime, the engineering stress or $\sigma_{\mathrm{E}}$ is between 0.14 and $0.24 \mathrm{MPa}$ ); and then finally, above $f_{\mathrm{s}}=0.97$, it increases again up to $f_{\mathrm{s}}=1.0$ (at this point $\sigma_{\mathrm{E}}$ is between 0.21 and $0.28 \mathrm{MPa}$ ). We also observe from the data that the lowest cooling rate $\left[0.1 \mathrm{~K} / \mathrm{s}\left(0.1^{\circ} \mathrm{C} / \mathrm{s}\right)\right]$ produces the highest force as the solid fraction increases above 0.88 . 


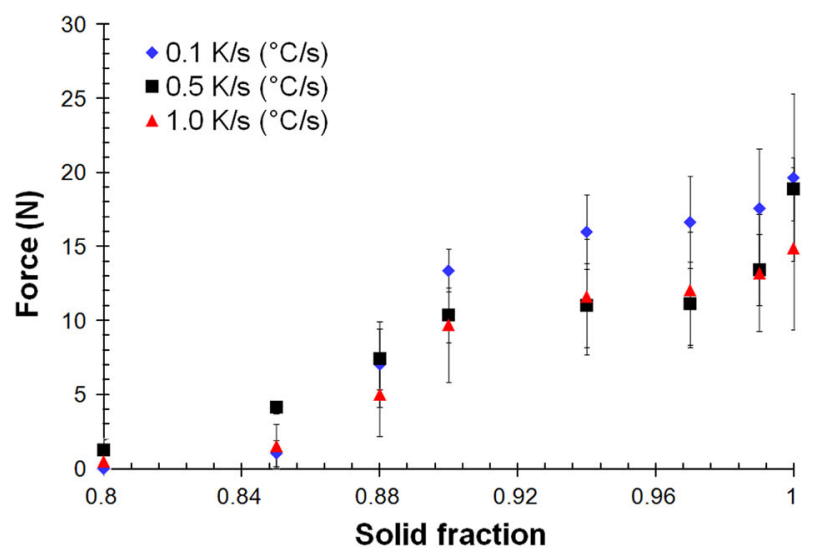

(a)

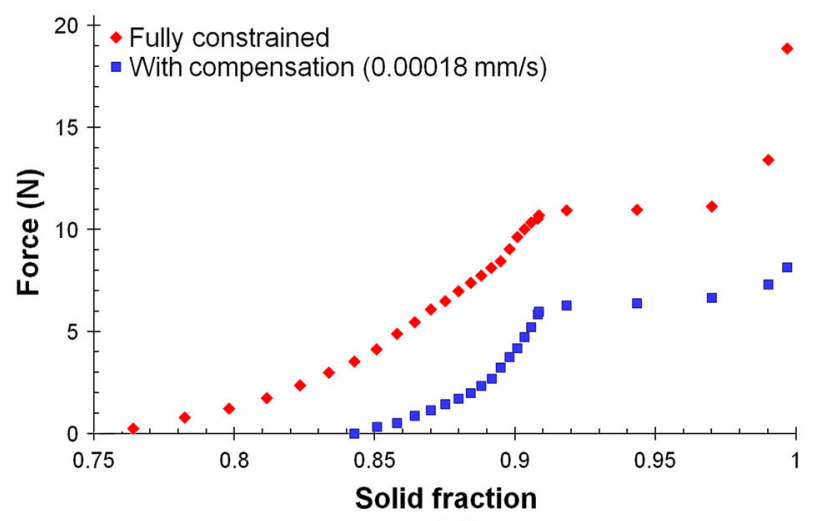

(b)

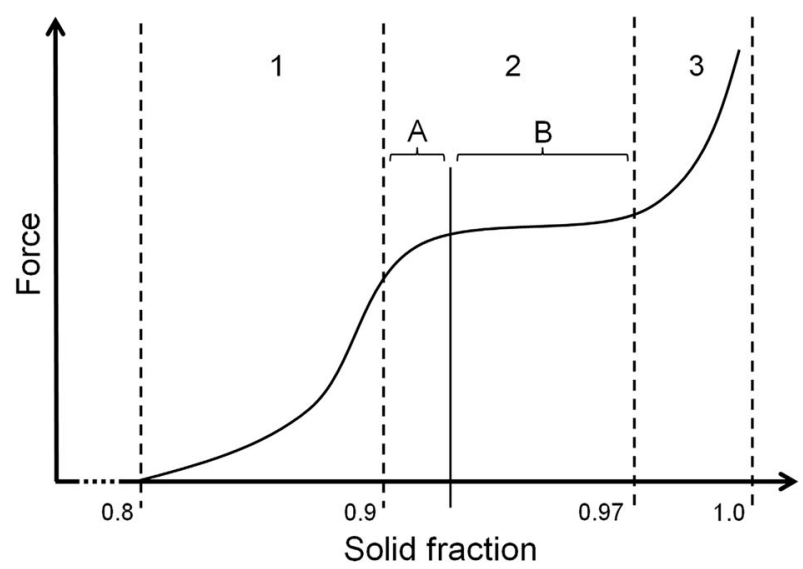

(c)

Fig. 3-Average measured force versus solid fractions during cooling of constrained samples for three cooling rates $(a)$ and the comparison of averaged force-displacement curve at $0.5 \mathrm{~K} / \mathrm{s}\left(0.5^{\circ} \mathrm{C} / \mathrm{s}\right)$ with compensation mode $(b)$. Different mechanical regions of force versus solid fraction curve $(c)$.

Figure 3(b) shows that the measured force on forcecompensation mode is lower than that in the constrained mode. This is because the compensated test condition has a lower strain rate compared with the constrained test, thus due to the viscoplastic effect resulting in lower exerted force. In addition, the mush feeding is better compared with the constrained test due to the less strain rate exerted by the sample. Such a figure also demonstrates a typical force shootout at the end of solidification (at approximately $f_{\mathrm{s}}=0.97$ ). This may indicate an advanced grain coalescence point, thus giving the alloy a significantly stronger structure. This phenomenon was also observed elsewhere, ${ }^{[13]}$ and indeed, the coalescence in AA6061 was found to be approximately at $f_{\mathrm{s}}=0.97$ which is in a good agreement with the result in this experiment and our previous study in AA7050 ${ }^{[14]}$ From such a study, we also found that the steep increase in strength starts from $f_{\mathrm{s}}=0.97$, which is approximately at the end of the eutectic solidification (please refer to Figure 1).

From Figures 3(a) and (b), we can see that although the force value depends on the testing conditions, the shapes of the force vs solid fraction curves are relatively similar - the force increases up to $f_{\mathrm{s}}=0.9$ and then flattens up to $f_{\mathrm{s}}=0.97$ to finally increase again up to fully solid state $\left(f_{\mathrm{s}}=1.0\right)$. Figure $3(\mathrm{c})$ shows a schematic description of these different mechanical regimes. In region 1, the material mainly starts to build up mechanical strength because of grain locking and welding (formation of solid bridges). Since there are quite sufficient amounts of liquid phase present between the grains, even though hot tear initiates, it can still be healed by the liquid phase. As the material continues to solidify (region 2), the force starts to level-off and forms a plateau between $f_{\mathrm{s}}=0.9$ and $f_{\mathrm{s}}=0.97$. We can suggest that at the beginning of the plateau-approximately $f_{\mathrm{s}}=0.9$ (region 2A), hot tears initiate. Other studies $^{[13,15]}$ reported that $f_{\mathrm{s}}=0.9$ is the end of interdendritic feeding regime, which means beyond such a solid fraction, crack healing by liquid feeding will be difficult because of the discontinuous feeding path. Then, as material continues to solidify, the force level continues to be flat up to $f_{\mathrm{s}}=0.97$ (region 2B). This phenomenon suggests a balancing act between the increasing intrinsic material strength due to the increase of solid fraction and the propagation of the initiated hot tear. This is also supported by our previous study ${ }^{[14]}$ which showed that the lowest ductility occurs between $f_{\mathrm{s}}=0.9$ and $f_{\mathrm{s}}=0.97$. It corresponds to the area called brittle temperature range where the material is prone to hot tearing. ${ }^{[16]}$ Then, as solid fraction increases over 0.97 (region 3), the force increases again. As explained in the previous paragraph, in this region, the material enters the advanced coalescence regime, and it has sufficient strength to resist hot-tear propagation until it is fully solid. This finding is also reported by other studies ${ }^{[13,14]}$ that advanced coalescence in aluminum alloy of series 6061 and 7050 is approximately at $f_{\mathrm{s}}=0.97$.

In addition, Figure 3(a) shows that the error bars generally become larger as the solid fraction increases. The increase becomes significantly noticeable starting at solid fraction of 0.88 . This is because at a lower solid fraction (i.e., below $f_{\mathrm{s}}=0.88$ ), there are still open feeding channels with approximately homogeneous width and spatial distribution. The strength of the material is mainly governed by the amount of solid fraction. However, as the material reaches the end of interdendritic feeding (i.e., around $f_{\mathrm{s}}=0.9$ ), the strength of the material not only depends on the solid fraction but also depends on the distribution of the 


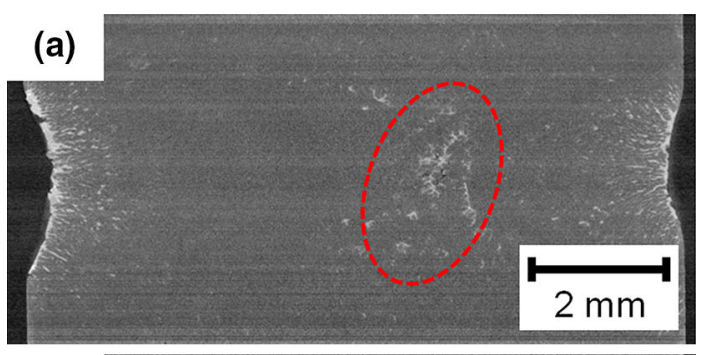

(b)

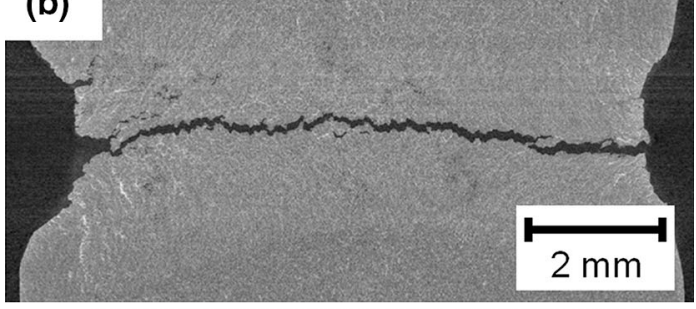

(c)

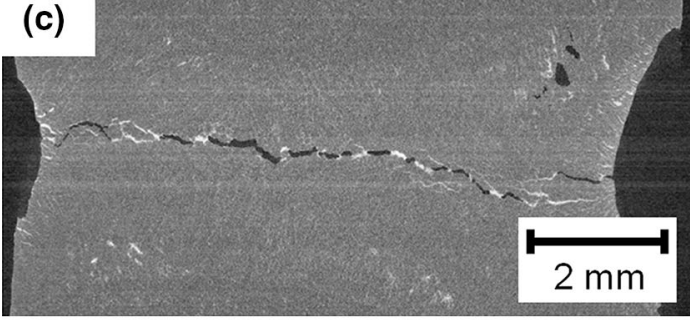

(d)

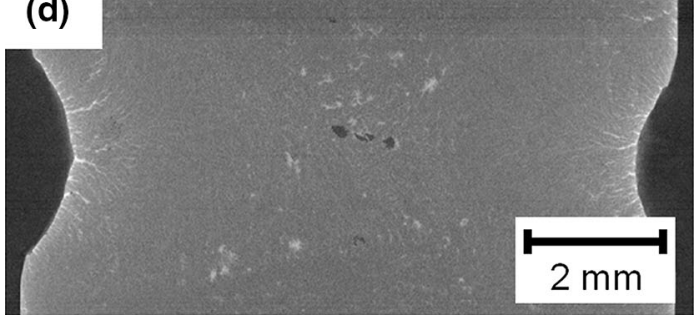

Fig. 4-Examples of axial cross section imaged by XMT of samples tested under different conditions: (a) $0.1 \mathrm{~K} / \mathrm{s}\left(0.1^{\circ} \mathrm{C} / \mathrm{s}\right)$ constrained; (b) $1.0 \mathrm{~K} / \mathrm{s}\left(1.0^{\circ} \mathrm{C} / \mathrm{s}\right)$ constrained; $(c) 0.5 \mathrm{~K} / \mathrm{s}\left(0.5^{\circ} \mathrm{C} / \mathrm{s}\right)$ constrained; and $(d) 0.5 \mathrm{~K} / \mathrm{s}\left(0.5^{\circ} \mathrm{C} / \mathrm{s}\right)$ with compensation.

formed cracks or redistributed eutectics. These features have less homogeneous distribution in terms of location and size within the sample and can vary from test to test, thus giving a wider range of mechanical response.

\section{B. XTM Imaging}

Figure 4 demonstrates that the XTM technique can provide detailed microstructural information based on the density of different phases of the alloy. Air or void spaces appear in black, the aluminum matrix is represented by gray, while eutectic phases that contain heavier elements, for instance $\mathrm{Al}_{2} \mathrm{CuMg}$ (S-phase), $\mathrm{Al}_{2} \mathrm{Mg}_{3} \mathrm{Zn}_{3}$ (T-phase) and $\mathrm{MgZn}_{2}$ (M-phase), ${ }^{[17,18]}$ appear as lighter gray.

At the lowest cooling rate in the series $[0.1 \mathrm{~K} / \mathrm{s}$ $\left.\left(0.1^{\circ} \mathrm{C} / \mathrm{s}\right)\right]$ in the constrained mode (Figure 4(a)), we observe the accumulation of eutectic phases in the center part of the sample (within dashed ellipse of Figure 4(a)) and smaller voids with typical size between 150 and
$180 \mu \mathrm{m}$ within the eutectic region. This finding is coherent with the result in previous observation. ${ }^{[8]}$ This shows us that at the lowest cooling rate, the microstructure has enough time to respond to the deformation, thus giving adequate feeding to the deformed part of the sample. The feeding continues in the eutectic solidification regime with the enriched remaining liquid, leading to the formation of some bright patches and only a small number of voids are produced in that area. Such structural features are called healed microcracks. ${ }^{[19]}$

At the highest cooling rate $\left[1.0 \mathrm{~K} / \mathrm{s}\left(1.0^{\circ} \mathrm{C} / \mathrm{s}\right)\right]$ in the constrained mode (Figure 4(b)), the hot-tearing damage is well developed, and the sample is almost torn apart. Furthermore, eutectic phase is uniformly distributed in the solidified volume. At such a cooling rate, the structure may not have adequate time to respond to the deformation and redistribute eutectic liquid to heal the created void. In addition, the propagation of the initiated hot tear has already taken place in the sample as the crack crosses the entire sample diameter, and only a few bridges link the two parts of the sample.

Figure 4(c) shows that as the cooling rate decreases to $0.5 \mathrm{~K} / \mathrm{s}\left(0.5^{\circ} \mathrm{C} / \mathrm{s}\right)$, the eutectic feeding becomes more active than in the case of $1.0 \mathrm{~K} / \mathrm{s}\left(1.0^{\circ} \mathrm{C} / \mathrm{s}\right)$, thus compensating some portion of the deformation and acting as the "last glue" that prevents the sample from being completely torn apart by the hot tear.

When the force compensation is applied during the test at a moderate cooling rate $\left[0.5 \mathrm{~K} / \mathrm{s}\left(0.5^{\circ} \mathrm{C} / \mathrm{s}\right)\right.$, Figure 4(d)], the hot-tearing development is much reduced. Such compensation technically is a displacement in the opposite direction to the thermal contraction applied at a constant rate, thus reducing the severity of hot-tear development. In such a condition, we can still see some bright patches in the vicinity of the created void signifying that eutectic feeding is active to heal the void creation, although the amount is less significant compared with the lowest cooling rate. This can be linked with the time availability for the eutectic to distribute itself within the structure.

Summarizing the results from different testing conditions, we can suggest that this alloy is sensitive to cooling rate. This is shown by less damaged structure produced at the lowest cooling rate $\left[0.1 \mathrm{~K} / \mathrm{s}\left(0.1^{\circ} \mathrm{C} / \mathrm{s}\right)\right]$ owing to the extended eutectic feeding and on the other hand, the remarkable amount of hot-tear damage developed at the highest cooling rate $\left[1.0 \mathrm{~K} / \mathrm{s}\left(1.0^{\circ} \mathrm{C} / \mathrm{s}\right)\right]$. The reason that the significant hot tear developed at such a cooling rate, which would be considered relatively low during DC casting ${ }^{[20]}$ is the limited size of the liquid metal reservoir, which is linked to the size of the melted zone in the samples, whereas in the DC casting case the liquid aluminum is continuously added to the sump, improving the feeding of the mush. The fact that most of hot-tear development reflects the highest cooling rate rather than the largest force shows that the role of feeding and deformation rate (cooling rate) may be determining in the hot-tear development. ${ }^{[21-23]}$

Figures 5(b)-(e) show the result of 3D void reconstruction of samples tested at different conditions; the void is represented by white objects; and the aluminum 


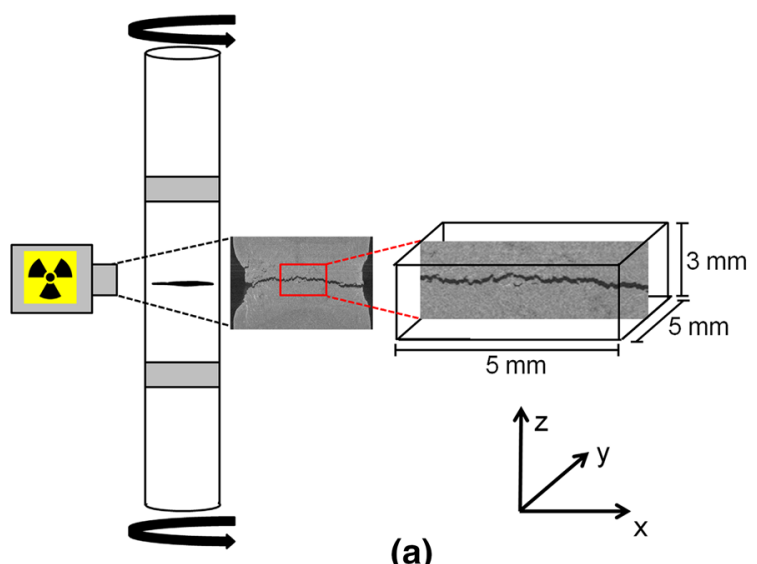

(a)

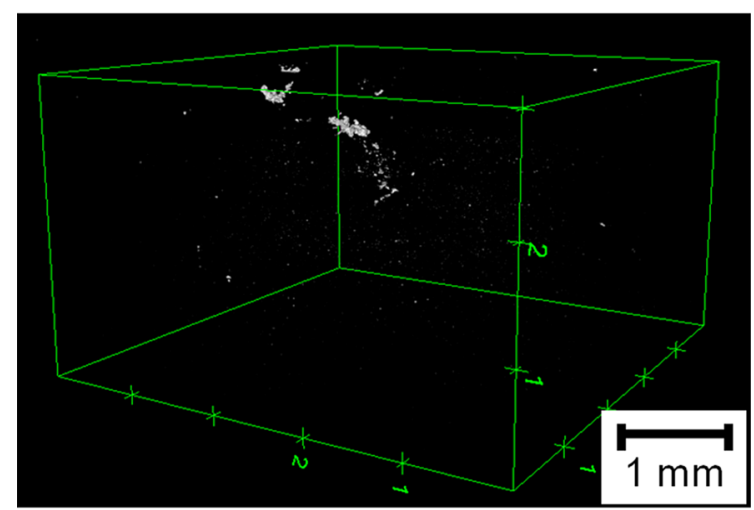

(b)

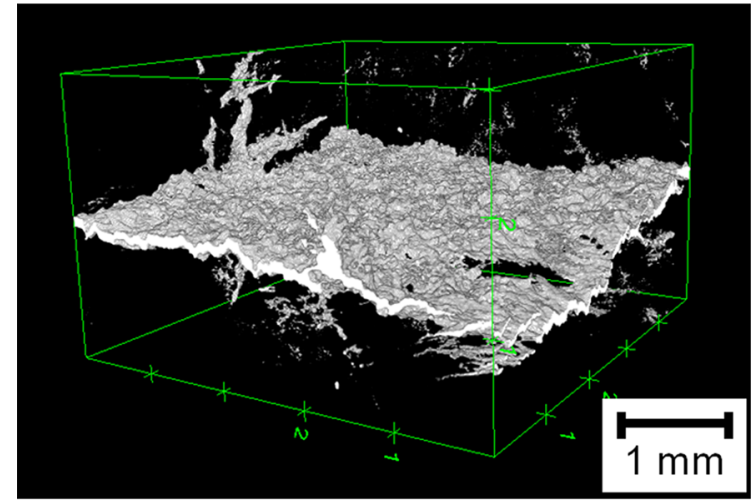

(c)

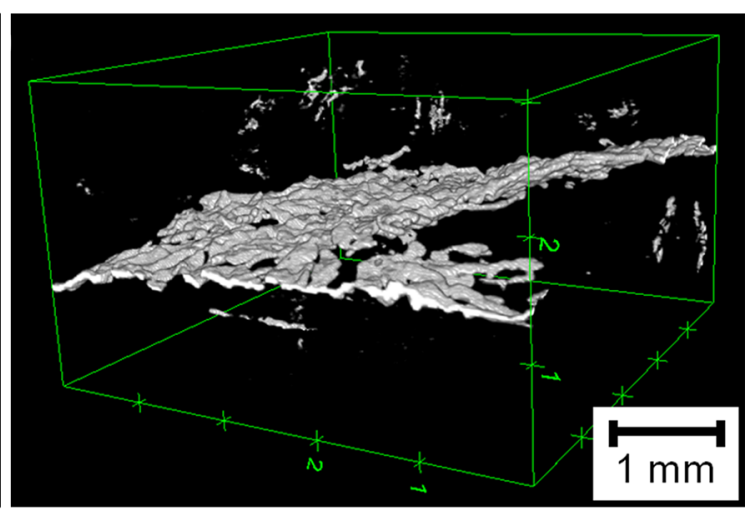

(d)

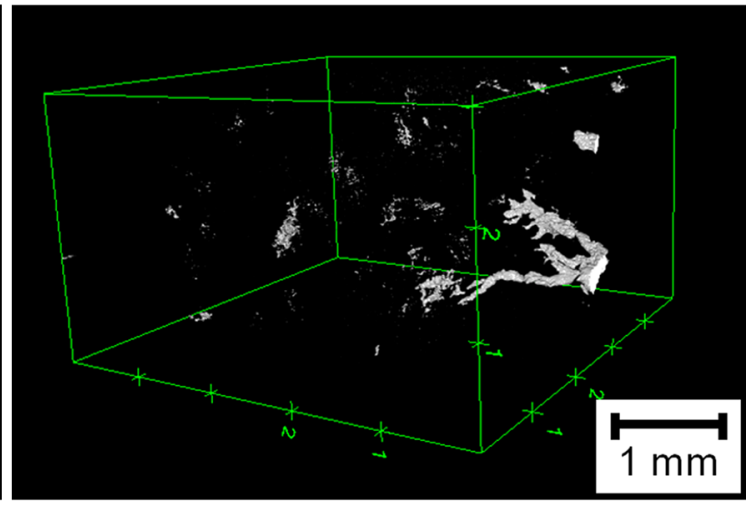

(e)

Fig. 5-Position of the bounding box with respect to the sample $(a)$. The 3D void space reconstruction of the XTM data from samples with different testing conditions: $(b) 0.1 \mathrm{~K} / \mathrm{s}\left(0.1^{\circ} \mathrm{C} / \mathrm{s}\right)$ constrained; $(c) 1.0 \mathrm{~K} / \mathrm{s}\left(1.0{ }^{\circ} \mathrm{C} / \mathrm{s}\right)$ constrained; $(d) 0.5 \mathrm{~K} / \mathrm{s}\left(0.5^{\circ} \mathrm{C} / \mathrm{s}\right)$ constrained; and $(e) 0.5 \mathrm{~K} / \mathrm{s}$ $\left(0.5^{\circ} \mathrm{C} / \mathrm{s}\right)$ with compensation. White objects are voids, and black background represents the matrix.

matrix is the background. The bounding box $(5 \times 5$ and $3 \mathrm{~mm}$ in height) is smaller than the sample's cross section $(9.5 \mathrm{~mm})$ and encapsulates the central and the most deformed area of the samples (Figure 5(a)). In Figure 5(b), we observe that due to the extended eutectic feeding seen in Figure 4(a), such a testing condition produces only a small amount of void space. While in Figures 5(c) and (d), we observe a planar hot tear, which has such severity that we could not use these samples for further experimentation. Figure 5(e) shows that voids that appear as a simple geometry in 2D planes actually have much more complex geometry if we extend the analysis to the third dimension. This flaunts the importance of a full $3 \mathrm{D}$ reconstruction of the hot tear, as we will need to relate such a complex geometry with the cold-crack initiator when using the samples for validation of the cold-cracking criterion. ${ }^{[3]}$ To summarize, the cracks in Figures 5(c) and (d) extended to the surface of the bounding box, while in Figures 5(b) and (e), cracks are encapsulated within the samples.

The results on damage characterization (Figures 4, 5) along with the results on force development (Figure 3(b)) 


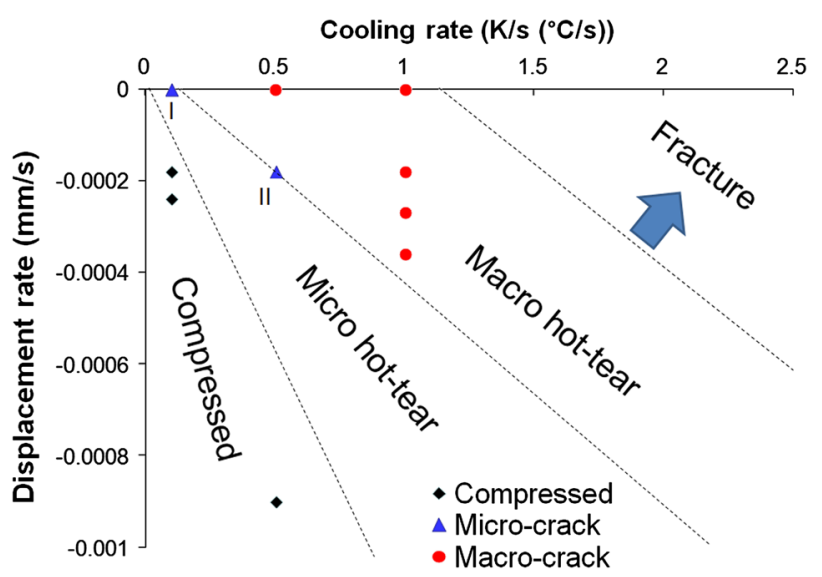

Fig. 6-Map of regimes of hot-tear formation as a function of two experimental variables, cooling rate, and compensation rate.

allow us to conclude that it is possible to qualitatively estimate the amount of hot tearing inside the sample during the test. If the force development is relatively low throughout the process, then more damage is developed as the alloy accommodates the stress by developing voids and cracks; and vice versa.

\section{Mapping of Hot-Tearing Regime}

From the force-temperature measurements and 3D reconstruction of XTM images, we propose a hot-tear development map that represents different testing regimes associated with the extent of hot tears by varying two test variables: cooling rate and displacement compensation rate. Figure 6 is the map based on the current experimental data. The first regime is compression where the compensation rate exceeds the fullcompensation rate; thus, negative or compression force in the force-temperature measurement is produced. Full-compensation rate is the compensation rate needed to keep the force equal to zero, and such a value depends on the cooling rate of the experiment. In this regime, there can be no hot tearing since the pressure is positive inside the mush. The second regime can be called the microscopic hot-tearing regime. In this regime, the compensation rate is just below the full-compensation rate, thus producing a limited amount of hot tears. There are two subregimes of the microscopic hot-tearing regime- - low cooling rate with nil-to-low compensation rate regime (type-I in Figure 6) and high cooling rate with medium-to-high compensation rate (type-II in Figure 6). For the former subregime, the low amount of hot tears is owing to the sufficient feeding condition, while the latter is due to the low total strain rate exerted by the sample because of the compensation condition. The next regime represents macroscopic hot-tear development, thus rendering the samples unusable for further experimentation. The final regime is complete fracture where the compensation rate is significantly lower than the full-compensation rate. The boundaries between these regimes may vary for different alloys and also may not necessarily have a sharp transition or divided linearly as hot tearing is inherently a complex and nonlinear phenomenon. ${ }^{[21,23]}$

The settings in the microscopic hot-tearing regime are suitable to produce a controlled hot tear that can be used for further cold-cracking validation experiment. A sample produced in this regime can be subsequently machined to a smaller diameter to remove the void structure formed by the thermocouple. Then, such a sample can be tensile tested at room temperature. The goal of this test is to see the correlation between the size and geometry of the produced micro hot tear (obtained from quantitative image analysis of X-ray tomography data) with respect to the room-temperature fracture strength. Such information can be further used to validate the existing cold-cracking criterion. ${ }^{[3,24]}$

\section{CONCLUSIONS}

In the current study, we demonstrated an experimental method that has the potential to control hot-tear development in a small-scale solidification process. Such a method is needed to produce samples for the validation of the connection between hot tearing and cold cracking. By controlling two variables during solidification, i.e., cooling rate and compensation rate, we proposed four regimes that signify the levels of the created hot tears: compressed mode, microscopic hottear, macroscopic hot-tear, and failure. The samples that are produced within the microscopic hot-tear regime can be used for further cold-cracking experiments. Moreover, from the obtained results, we also suggest that, when it comes to hot-tear development, the cooling rate and feeding of the mushy zone during solidification may be more important variables compared with the exerted force.

\section{ACKNOWLEDGMENTS}

This research was carried out within the Materials innovation institute (www.m2i.nl) research framework, project no. M42.5.09340. The authors would like to express their gratitude to Dr. D. Ruvalcaba and Mr. J. van Oord (Tata Steel Nederland Technology B.V.), and also Dr. R. Sauermann (Aleris Europe) for their support and input. In addition, the authors also would like to thank Mr. W. Verwaal (CITG faculty, TU Delft) for his help in X-ray microtomography imaging of the samples. The support from the Modelling-assisted INnovation for Aluminum DC Casting process (MINAC) community is greatly appreciated.

\section{REFERENCES}

1. J.C. Williams and E.A. Starke, Jr: Acta Mater., 2003, vol. 51, pp. 5775-99.

2. M. Lalpoor, D.G. Eskin, and L. Katgerman: Mater. Sci. Eng. A, 2008, vol. 497, pp. 186-94 
3. M. Lalpoor, D.G. Eskin, D. Ruvalcaba, H.G. Fjær, A. Ten Cate, N. Ontijt, and L. Katgerman: Mater. Sci. Eng. A, 2011, vol. 528, pp. $2831-42$.

4. Q. Han, S. Viswanathan, D.L. Spainhower, and S.K. Das: Metall. Mater. Trans. A, 2001, vol. 32A, pp. 2908-10.

5. J.M. Drezet, O. Ludwig, C. Jacquerod, and E. Waz: Int. J. Cast Met. Res., 2007, vol. 20, pp. 163-70.

6. D.G. Eskin, M. Lalpoor, and L. Katgerman: Light Metals, TMS, San Diego, CA, 2011, pp. 669-74.

7. T. Subroto, A. Miroux, D. Mortensen, M. M'Hamdi, D.G. Eskin, and L. Katgerman: Modeling of Casting Welding and Advanced Solidification Process XIII (MCWASP XIII), IOP Conference Series: Materials Science and Engineering: Schladming, 2012, p. 012068 .

8. S. Terzi, L. Salvo, M. Suéry, N. Limodin, J. Adrien, E. Maire, Y. Pannier, M. Bornert, D. Bernard, M. Felberbaum, M. Rappaz, and E. Boller: Scripta Mater., 2009, vol. 61, pp. 449-52.

9. A.B. Phillion, R.W. Hamilton, D. Fuloria, A.C.L. Leung, P. Rockett, T. Connolley, and P.D. Lee: Acta Mater., 2011, vol. 59, pp. $1436-44$.

10. C. Puncreobutr, P.D. Lee, R.W. Hamilton, B. Cai, and T. Connolley: Metall. Mater. Trans. A, 2013, vol. 44A, pp. 5389-95.

11. M. Lalpoor, D.G. Eskin, and L. Katgerman: Metall. Mater. Trans. A, 2010, vol. 41A, pp. 2425-34.

12. J. Schindelin, I. Arganda-Carreras, E. Frise, V. Kaynig, M. Longair, T. Pietzsch, S. Preibisch, C. Rueden, S. Saalfeld, B. Schmid, J.Y. Tinevez, D.J. White, V. Hartenstein, K. Eliceiri, P.
Tomancak, and A. Cardona: Nat. Methods, 2012, vol. 9, pp. 67682 .

13. E. Giraud, M. Suery, and M. Coret: Metall. Mater. Trans. A, 2010, vol. 41A, pp. 2257-68.

14. T. Subroto, A. Miroux, D.G. Eskin, K. Ellingsen, A. Marson, M. M'Hamdi, and L. Katgerman: $13^{\text {th }}$ International Conference on Fracture, Beijing, 2013.

15. D. Fabrègue, A. Deschamps, M. Suéry, and W.J. Poole: Metall. Mater. Trans. A, 2006, vol. 37A, pp. 1459-67.

16. D.G. Eskin, Suyitno, and L. Katgerman: Prog. Mater. Sci., 2004, vol. 49, pp. 629-711.

17. J.D. Robson: Mater. Sci. Eng. A, 2004, vol. 382, pp. 112-21.

18. L.F. Mondolfo: Aluminum alloys: Structure and properties, Butterworths \& Co Ltd, London, 1976.

19. Suyitno, D.G. Eskin, and L. Katgerman: Mater. Sci. Eng. A, 2006, vol. 420, pp. 1-7.

20. D.G. Eskin: Physical Metallurgy of Direct Chill Casting of Aluminum Alloys (Advances in Metallic Alloys), CRC Press, Taylor \& Francis group, LLC, 2008.

21. W.M. Van Haaften, W.H. Kool, and L. Katgerman: J. Mater. Eng. Perform., 2002, vol. 11, pp. 537-43.

22. Suyitno, W.H. Kool, and L. Katgerman: Metall. Mater. Trans. A, 2005, vol. 36A, pp. 1537-46.

23. D.G. Eskin and L. Katgerman: Metall. Mater. Trans. A, 2007, vol. 38A, pp. 1511-19.

24. M. Lalpoor, D.G. Eskin, and L. Katgerman: Metall. Mater. Trans. A, 2009, vol. 40A, pp. 3304-13. 